\title{
HUBUNGAN ANTARA POWER OTOT LENGAN DENGAN KEMAMPUAN SERVIS ATAS PERMAINAN BOLA VOLI PADA SISWA SMA NEGERI 2 MAWASANGKA
}

\author{
Muhammad Rusli ${ }^{1}$ Abdul Saman ${ }^{2}$ Hasanuddin Jumareng ${ }^{3}$
}

\begin{abstract}
Abstrak : Tujuan penelitian ini adalah untuk mengetahuihubungan powerotot Lengan dengan kemampuan Servis Atas Permainan Bola Voli pada Siswa SMA Negeri 2 Mawasangka. Populasi dalam penelitian yaitu berjumlah 170 orang siswa kelas IX. Dimana siwa putra berjumlah 102 orang dan putri berjumlah 68 orang.Teknik pengambilan sampel dilakukan dengan teknik purposive randomsampling dengan kriteria yaitu siswa yang berjenis kelamin putra dan dapat melakukan teknik servis atas dalam permainan bola voli, yang berjumlah 102 orang. Kemudian di random, dan peneliti akan mengambil 35\% dari jumlah populasi yaitu sampel sebanyak 36 orang.Instrument yang digunakan yaitu tesmedicine ball putuntuk mengukur kemampuan power otot lengan dan tes kemampuan servis atas permainan bola voli. Data penelitian dianalisis dengan teknik statistik korelasi product moment.

Berdasarkan analisis data maka dalam penelitian ini dapat disimpulkan bahwa terdapat hubungan yang signifikan antara power otot lengan dengan kemampuan servis atas permainan bola voli, dimana koefisien korelasi (rxy) = $0,73>$ nilai $r$ tabel $=0,329$, dengan koefisien determinasi $r^{2}=0,73^{2}=0,54$ atau $54 \%$ artinya powerotot lengan memberikan kontribusi atau sumbangan terhadap kemampuan servis atas permainan bola voli sebesar 54\%. Sedangkan $46 \%$ dipengaruhi oleh unsur kondisi fisik lainnya misalnyaketepatan, kelenturan dan koordinasi.
\end{abstract}

Kata Kunci : power, otot lengan, servis atas, bola voli

\section{PENDAHULUAN}

Olahraga adalah segala kegiatan yang sistematis untuk mendorong, membina, serta mengembangkan potensi jasmani, rohani, dan sosial (UU Sistem Keolahragaan Nasional No. 3 Tahun 2005). Keberadaan olahraga sekarang ini sudah menjadi bagian kegiatan masyarakat, dari anak-anak sampai orang tua, dan tidak lagi dipandang sebelah mata. Salah satu cabang olahraga yang berkembang dan digemari masyarakat adalah bola voli. Tiap orang mempunyai tujuan yang berbeda-beda dalam melakukan olahraga bola voli, ada yang bertujuan untuk memperluas pergaulan, memperbanyak teman, rekreasi, kesehatan, dan tidak sedikit dari mereka yang berusaha untuk meraih prestasi.

Tuntutan prestasi yang tinggi dan semakin berkembangnya olahraga bola voli akan membutuhkan beberapa perkembangan, baik secara teknik maupun taktik. Dalam perkembangannya, sekarang permainan bola voli telah menjadi olahraga kompetitif resmi yang selalu diperlombakan dalam setiap pesta olahraga. Orientasi pembinaannya lebih mengarah pada

\footnotetext{
${ }^{1}$ Penulis adalah Staf Edukatif Jurusan Penjaskesrek FKIP UHO

${ }^{2}$ Penulis adalah Staf Edukatif Jurusan Penjaskesrek FKIP UHO

${ }^{3}$ Penulis adalah Staf Edukatif Jurusan Penjaskesrek FKIP UHO
} 
pencapaian prestasi. Akan tetapi nilai rekreasi tidak akan hilang bahkan akan selalu melekat. Prestasi seorang atlet sangat ditentukan oleh kualitas pelatih dan progam latihannya, sehingga didirikanlah klub sebagai wadah pelatihan dan pembinaan atlet (Amung Ma'mun dan Toto Subroto, 2001).

Keterampilan teknik dalam permainan bola voli meliputi: servis, passing, umpan (set up), smash (spike), dan bendungan (block). Untuk dapat mengembangkan mutu prestasi, teknik dasar dalam permainan bola voli harus benar-benar dipelajari salah satu teknik dasar adalah servis.Pada jaman sekarang ini servis tidak lagi sebagai tanda saat dimulainya permainan ataupun sekedar menyajikan bola tetapi servis diartikan sebagai suatu serangan yang pertama kali bagi regu yang melakukan servis (Suharno HP,1985). Karena pukulan servis berperan besar atas terjadinya perolehan poin maka pukulan servis harus: meyakinkan, terarah, keras, dan menyulitkan lawan (Nuril Ahmadi,2007).Saat ini banyak diketahui bahwa para atlet bola voli sering menggunakan servis atas, dengan salah satu alasan karena servis atas merupakan pukulan utama penyerangan dalam usaha mencapai kemenangan. Oleh karena itu setiap pemain dalam satu team harus benar-benar menguasai servis atas dengan baik, karena servis atas merupakan serangan utama dan lebih sulit untuk diterima oleh lawan.

Penguasaan teknik dasar yang sempurna menjadi dasar untuk mengembangkan prestasi permainan itu sendiri. Penguasaan teknik dasar bola voli merupakan salah satu unsur yang turut menentukan menang atau kalahnya suatu tim didalam pertandingan, disamping unsur-unsur kondisi fisik, taktik, mental serta postur tubuh yang mendukung. Kondisi fisik atau aspek biomotorik menurut (Nuril Ahmadi,2007) terdiri dari kecepatan, daya tahan, keseimbangan,power, kekuatan, kelenturan, koordinasi, kelincahan, ketepatan, dan reaksi. Pada pemain yang berperan dalam melakukan servis bawah tentunya tidak perlu sama kadar kemampuan power dengan seorang pemain yang berperan dalam melakukan servis atas, jika dilihat dari gerakan pada bagian tubuh, memerlukan power otot lengan, karena kemampuan fisik tersebut sangat penting pada pemain bola voli agar dapat melakukan pukulan tajam atau keras yang bisa mematikan lawan untuk mendapatkan perolehan poin.

Penjelasan diatas jelas bahwa dalam melakukan servis atas kita memerlukan power otot lengan. Untuk mendapatkan gambaran yang jelas tentang bagaimana power otot lengan dengan kemampuan servis atas dalam permainan bola voli perlu dilakukan kajian ilmiah melalui proses penelitian. Adapun yang menjadi objek dan subjek penelitian ini adalah siswa SMA Negeri 2Mawasangka. Adapun yang menjadi pertimbangan memilih sekolah tersebut karena dari observasi awal bahwa pada saat latihan bola voli siswa yang mencoba melakukan servis atas masih ada beberapa yang memiliki kemampuan servis kurang baik dan sebagian siswa lainnya memiliki kemampuan servis atas yang baik. Seringkali siswa dalam servis atas bola tidak mampu menyebrang dari net, Hal tersebut di karenakan power otot lengan yang kurang kuat yang dimiliki siswa masih kurang. Oleh karena itupenulis mencoba untuk melakukan kajian melalui penelitian dengan tema "hubungan antara powerotot lengan dengan kemampuan servis atas permainan bola voli pada siswa SMA Negeri 2 Mawasangka".

\section{METODE}

Penelitian ini termasuk dalam kategori penelitian deskriptif korelasional yang dimana peneliti ingin mengetahui hubungan power otot lengan dengan kemampuan servis atas dalam permainan bola voli. Adapun rancangan penelitian ini dapat divisualisasikan sebagai berikut: 


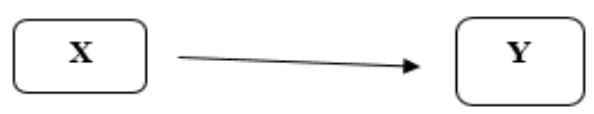

Keterangan:

Gambar. Desain Penelitian (Mia Kusumawati, 2015)

$\mathrm{X}=$ Power otot lengan

$\mathrm{Y}=$ Kemampuan servis atas

$\longrightarrow=$ Hubungan

Variabel dalam penelitian ini adalah sebagai berikut:

1. Variabel bebas adalah power otot lengan(X)

2. Variabel terikat adalah kemampuan servis atas (Y)

Agar tidak memberi panafsiran yang keliru tentang variabel yang dimaksud dalampenelitian ini maka perlu didefinisikan secara operasional yaitu sebagai berikut:

1) Powerotot lengan yang dimaksud dalam penelitian adalah jarak tester dalam melakukan gerakan melempar bola medicineseberat $3 \mathrm{~kg}$ sambil duduk dengan kedua tangan di atas kapala. Tanpa awalan bola dilempar dengan kedua tangan dari atas kepala kedepan sejauh-jauhnya dalam posisi duduk dalam satuan meter.

2) Ketepatan servis atas yang dimaksudkan dalam penelitian ini adalah skor yang diperoleh tester dalam melakukan servis atas sebanyak 6 kali kesempatan dimana terdapat angka sasaran.

Berdasarkan observasi pada sekolah SMA Negeri 2 Mawasangka, populasi dalam penelitian yaitu berjumlah 170 orang siswa kelas IX. Dimana siwa putra berjumlah 102 orang dan putri berjumlah 68 orang. Teknik pengambilan sampel dilakukan dengan teknik purposiverandom sampling dengan kriteria yaitu siswa yang berjenis kelamin putra dan dapat melakukan teknik servis atas dalam permainan bola voli, yang berjumlah 102 orang. Kemudian di random, dan peneliti akan mengambil $35 \%$ dari jumlah populasi yaitu sampel sebanyak 36 orang.

Adapun instrumen yang digunakan dalam penelitian ini yaitu instrumenuntuk mengukur power otot lengan dan instrumen untuk mengukur kemampuan servis atas dalam permainan bola voli.

1. Instrument power otot lengan

Instrument tes yang digunakan untuk mengukur power otot lengan adalah tes Medicine Ball-Put (Nurhasan,1986)

a. Tujuan : Tes ini bertujuan untuk mengukur power otot lengan

b. Alat : Bola medicine $3 \mathrm{~kg}$, meteran, kursi dan kapur. 
Muhammad Rusli, Abdul Saman : Hubungan Antara Power Otot Lengan Dengan Kemampuan Servis Atas Permainan Bola Voli Pada Siswa Sma Negeri 2 Mawasangka

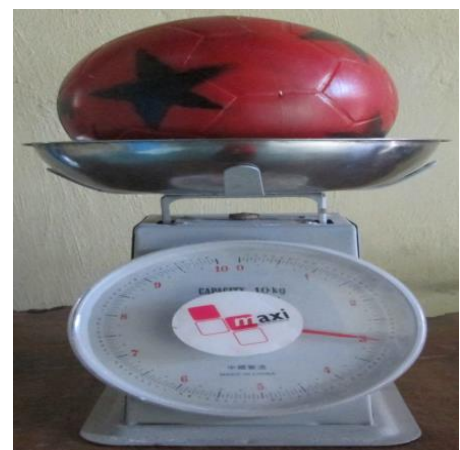

Gambar. Bola Medicine (modifikasi 3 kg)

Sumber: Nurhasan (1986)

c. Pelaksanaan:

1) Tester duduk tegak dikursi seutas tali dilingkarkan pada dada, ditarik kebelakang sehingga bersandar pada kursi. Hal ini untuk mencegah agar pada waktu mendorong tidak di bantu oleh gerakan badan ke depan.

2) Tester dengan menggunakan kedua tangan mendorong bola medicine tersebut ke depan sejauh mungkin.

3) Tes dilakukan sebanyak tiga kali, yang terbaik dicatat sebagai data penelitian.

d. Penilaian: jarak tolakan yang terjauh dari tiga kali perlakuan, yang diukur mulai dari tepi kaki kursi sampai batas atau tanda dimana awal jatuh bola medicine.

2. Instrument tes ketepatan servis atas bola voli

Instrument tes yang digunakan untuk mengukur ketepatan servis atas dilakukan dengan prosedur sebagai berikut:

a. Alat : Lapangan bola voli, net dan tiang net, antena 2 buah, bola voli 6 buah.

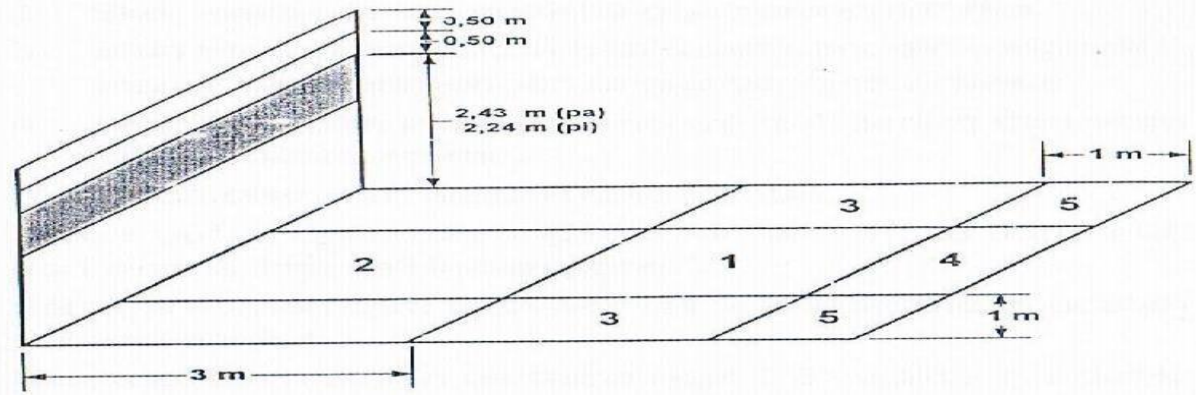

Gambar. Lapangan Bola Voli untuk Pelaksanaan Tes Servis

Sumber: Nurhasan (1986) 
Jurnal Ilmu Keolahragaan Vol. 17 (2), Juli-Desember 2018: 36 - 45

b. Petunjuk Pelaksanaan

1) Tester berada dalam daerah servis dan melakukan servis yang sah sesuai dengan peraturan permainan yang berlaku untuk servis.

2) Bentuk pukulan servis adalah bebas.

3) Kesempatan melakukan servis sebanyak 6 kali.

c. Cara menskor

Skor setiap servis ditentukan oleh tinggi bola waktu melampaui jaring dan angka sasaran dimana bola jatuh.

1) Bola yang melewati jaring diantara batas atas jaring dan tali setinggi $50 \mathrm{~cm}$, skor angka sasaran dikalikan tiga.

2) Bola yang melampaui jaring diantara kedua tali yang direntangkan, skor angka sasaran dikalikan dua.

3) Bola yang melampaui jaring lebih tinggi dari tali yang tertinggi, skor angka sasaran.

4) Bola yang menyentuh tali batas atas jaring, dihitung telah melampaui ruang dengan angka perkalian yang lebih besar.

5) Bola yang menyentuh garis batas sasaran dihitung telah mengenai sasaran dengan angka yang lebih besar.

6) Bola yang dimainkan dengan cara yang tidak sah atau bola menyentuh jaring dan atau jatuh di luar bagian lapangan di mana terdapat sasaran, skor : 0 .

Teknik untuk menguji hipotesis yang dikemukakan, maka data yang telah terkumpul dianalisis dengan teknik statistik infrensial dengan menggunakan rumus korelasi product momentsebagai berikut:

Korelasi Product Moment

$$
\mathrm{Rxy}=\frac{\mathrm{N} \sum \mathrm{XY}-\left(\sum \mathrm{X}\right)\left(\sum \mathrm{Y}\right)}{\sqrt{\left\{\mathrm{N} \sum \mathrm{X}^{2}-\left(\sum \mathrm{X}\right)^{2}\right\}\left\{\mathrm{N} \sum \mathrm{Y}^{2}-\left(\sum \mathrm{Y}^{2}\right)\right\}}}
$$

Keterangan:

$\mathrm{RXY}=$ Koefisien korelasi variabel $\mathrm{x}$ dan $\mathrm{y}$

$\mathrm{XY}=$ Jumlah hasil kali nilai $\mathrm{x}$ dan $\mathrm{y}$

$\sum \mathrm{X}=$ Jumlah nilai variabel $\mathrm{x}$

$\sum \mathrm{Y}=$ Jumlah nilai variabel $\mathrm{y}$

$\sum \mathrm{X}^{2}=$ Kuadrat nilai variabel $\mathrm{x}$

$\sum \mathrm{Y}^{2}=$ Kuadrat nilai variabel y

$\mathrm{N}=$ Jumlah sampel

Mengetahui tingkat korelasi tiap variabel maka digunakan peta korelasi sebagai berikut:

a. $0,00-0,20=$ korelasi sangat rendah

b. $0,21-0,40=$ korelasi rendah

c. $0,41-0,60=$ korelasi sedang

d. $0,61-0,80=$ korelasi tinggi

e. $0,81-1,00=$ korelasi sempurna. 
Muhammad Rusli, Abdul Saman : Hubungan Antara Power Otot Lengan Dengan Kemampuan Servis Atas Permainan Bola Voli Pada Siswa Sma Negeri 2 Mawasangka

\section{HASIL}

Hasil analisis statistik deskripsi yang dimaksud adalah rata-rata, standar deviasi, nilai maximum dan nilai minimum dari tiap variabel penelitian. Adapun hasil statistik deskriptif variabel penelitian dapat dilihat pada:

Tabel. Deskripsi Statistik PowerOtot Lengan (X)dan Kemampuan

$$
\text { Servis Atas dalam Permainan Bola Voli (Y) }
$$

\begin{tabular}{ccccc}
\hline Variabel & $\begin{array}{c}\text { Rata- } \\
\text { rata }\end{array}$ & $\begin{array}{c}\text { Standar } \\
\text { Deviasi }\end{array}$ & $\begin{array}{c}\text { Nilai } \\
\text { Maximum }\end{array}$ & $\begin{array}{c}\text { Nilai } \\
\text { Minimum }\end{array}$ \\
\hline $\mathbf{X}$ & 3,53 & 0,44 & 4,42 & 2,8 \\
\hline $\mathbf{Y}$ & 38,53 & 12,73 & 75 & 20 \\
\hline
\end{tabular}

Berdasarkan hasil analisis deskriptif pada tabel 1 dapat diketahui: a) rata-rata dari powerotot lengan (X) adalah 3,53 dengan standar deviasi 0,44 , b) rata-rata dari kemampuan servis atas dalam permainan bola voli (Y) adalah 38,53dengan standar deviasi 12,73, c) skor kemampuan maximal dari powerotot lengan (X) sampel adalah 4,42, sedangkan kemampuan minimalnya adalah 2,8, d) Skor maximal kemampuan servis atas dalam permainan bola voli sampel adalah 75 , sedangkan kemampuan minimalnya adalah 20 .

\section{Distribusi Frekuensi Power Otot Lengan dengan Kemampuan Servis Atas dalam Permainan Bola Voli}

Tabel. Distribusi Frekuensi Hasil PowerOtot Lengan (X)

\begin{tabular}{cccc}
\hline $\begin{array}{c}\text { Kelas } \\
\text { Interval }\end{array}$ & Frek Absolut $(\mathbf{f})$ & $\begin{array}{c}\text { Frek } \\
\text { Kumulatif(f.k) }\end{array}$ & Frek Relatif (\%) \\
\hline $2,8-3,09$ & 8 & 8 & 22,22 \\
\hline $3,10-3,39$ & 8 & 16 & 22,22 \\
\hline $3,40-3,69$ & 7 & 23 & 19,44 \\
\hline $3,70-3,98$ & 5 & 28 & 13,89 \\
\hline $3,99-4,28$ & 7 & 35 & 19,44 \\
\hline $4,29-4,58$ & 1 & 36 & 2,78 \\
\hline Jumlah & 36 & & 100,00 \\
\hline
\end{tabular}

Pada tabel 4.2 dapat dijelaskan bahwa: power otot lengan dalam inteval skor 2,8 3,09 sebanyak 8 orang $(22,22 \%)$, yang memiliki interval skor 3,10 - 3,39sebanyak 8 orang $(22,22 \%)$, yang memiliki interval skor 3,40 - 3,69sebanyak 7 orang $(19,44 \%)$, yang memiliki interval skor 3,70 - 3,98sebanyak 5 orang $(13,89 \%)$, yang memiliki interval skor 3,99 - 4,28sebanyak 7 orang (19,44\%), yang memiliki interval skor 4,29 4,58sebanyak 1 orang $(2,78 \%)$, jika di distribusipower otot lengan digambarkan dalam bentuk diagram batang, maka diperoleh seperti gambar. 
Jurnal Ilmu Keolahragaan Vol. 17 (2), Juli-Desember 2018: 36 - 45

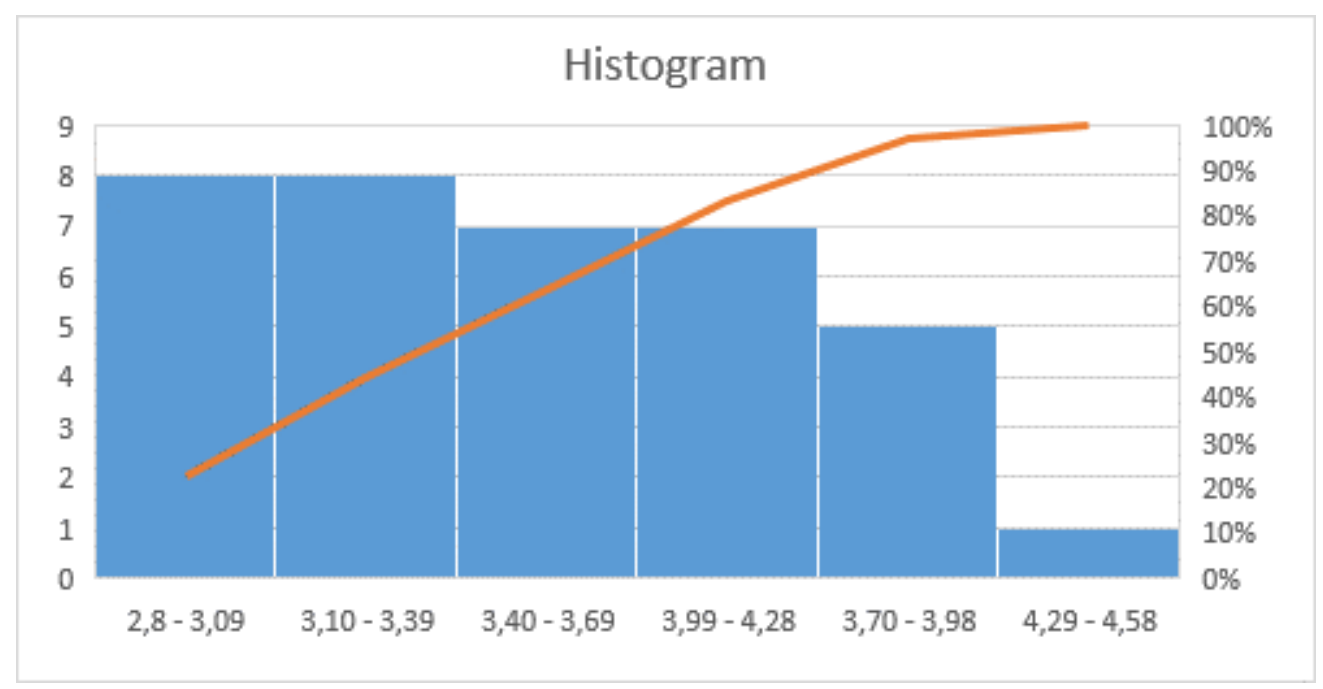

Gambar. Histogram Power Otot Lengan (X)

Tabel. Distribusi Frekuensi Hasil Kemampuan Servis Atas Permainan Bola Voli(Y)

\begin{tabular}{cccc}
\hline Kelas Interval & $\begin{array}{c}\text { Frek Absolut } \\
\text { (f) }\end{array}$ & $\begin{array}{c}\text { Frek } \\
\text { Kumulatif(f.k) }\end{array}$ & $\begin{array}{c}\text { Frek Relatif } \\
(\boldsymbol{\%})\end{array}$ \\
\hline $20-29$ & 9 & 9 & 25,00 \\
\hline $30-39$ & 14 & 23 & 38,89 \\
\hline $40-49$ & 7 & 30 & 19,44 \\
\hline $50-59$ & 3 & 33 & 8,33 \\
\hline $60-69$ & 1 & 34 & 2,78 \\
\hline $70-79$ & 2 & 36 & 5,56 \\
\hline Jumlah & 36 & & 100,00 \\
\hline
\end{tabular}

Tabel diatas dapat dijelaskan bahwa: kemampuan servis atas permainan bola voli dalam inteval skor 20 - 29sebanyak 9 orang (25.00\%), yang memiliki interval skor 30 39 sebanyak 14 orang (38.89\%), yang memiliki interval skor $40-49$ sebanyak 7 orang $(19,44 \%)$, yang memiliki interval skor 50 - 59sebanyak 3 orang $(8,33 \%)$, yang memiliki interval skor 60 - 69sebanyak 1 orang $(2,78 \%)$, yang memiliki interval skor 70 79 sebanyak 2 orang $(5,56 \%)$, jika di distribusipower otot lengan digambarkan dalam bentuk diagram batang, maka diperoleh seperti gambar. 
Muhammad Rusli, Abdul Saman : Hubungan Antara Power Otot Lengan Dengan Kemampuan Servis Atas Permainan Bola Voli Pada Siswa Sma Negeri 2 Mawasangka

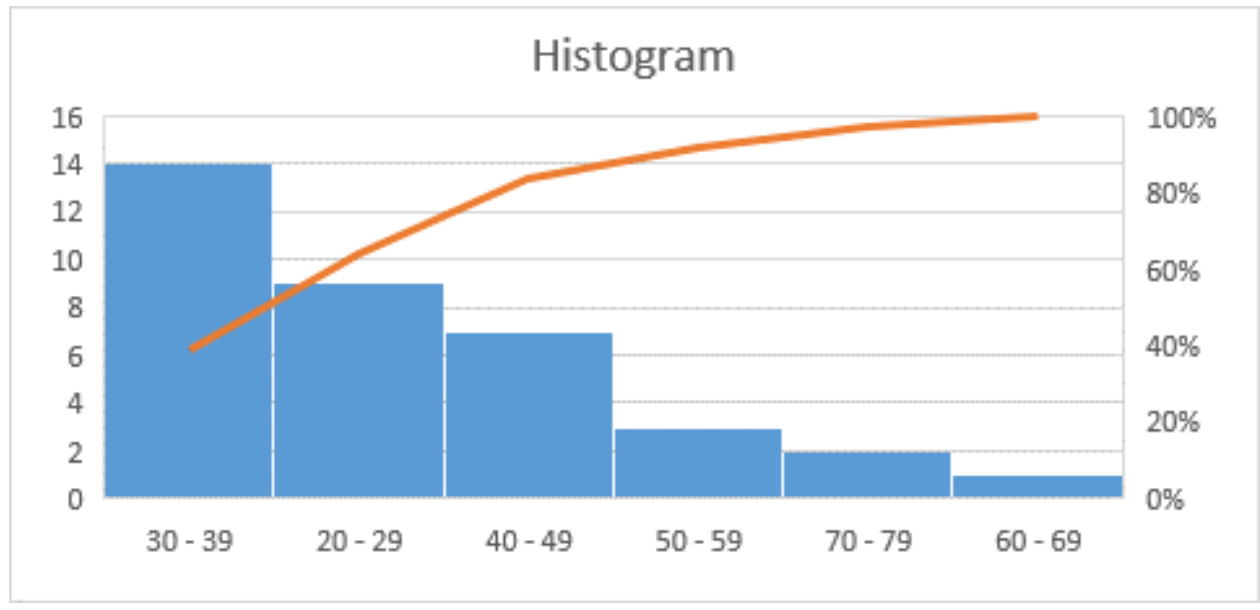

Gambar. Histogram Distribusi Hasil Kemampuan Servis Atas Permainan Bola Voli (Y)

Data diuji dengan menggunakan rumus korelasi product moment. Uji korelasi dapat dilihat pada lampiran III.

Tabel. Power Otot Lengan (X)dan Kemampuan Servis Atas Permainan Bola Voli (Y)

\begin{tabular}{cccc}
\hline $\begin{array}{c}\text { Korelasi } \\
\text { Variabel }\end{array}$ & $\begin{array}{c}\text { Koefisien } \\
\text { Korelasi }(\mathrm{r})\end{array}$ & $\begin{array}{c}\text { Koefisien } \\
\text { Determinasi }\left(\mathrm{r}^{2}\right)\end{array}$ & $\mathrm{r}$ tabel $(0,05: 36)$ \\
\hline $\mathrm{X}$ dengan $\mathrm{Y}$ & 0,73 & 0,54 & 0,329 \\
\hline
\end{tabular}

Berdasarkan Tabel dapat diketahui bahwa koefisien korelasi antara power otot lengan dengan kemampuan servis atas permainan bola voli $\left(\mathrm{r}_{\mathrm{XY}}\right)$ adalah sebesar 0,73. Untuk mengetahui kebermaknaan hubungan power otot lengan dengan kemampuan servisatas permainan bola voli $r_{X Y}$ yang diperoleh dibandingkan dengan nilai tabel korelasi product moment pada taraf signifikan 0,05 dengan jumlah sampel 36 diperoleh $\mathrm{r}$ tabel $=0,329$.

Nilai $r_{X Y}(0,73)>$ nilai $r_{\text {tabel }}(0,329)$, maka disimpulkan Ho ditolak. Artinya terdapat hubungan yang signifikan hubungan power otot lengan dengan kemampuan servis atas permainan bola voli.Koefisien determinasi antara kedua variabel $\left(\mathrm{r}^{2}\right)$ sebesar 0,54 dengan kata lain 54\% kemampuan servis atas permainan bola voli ditentukan olehpower otot lengan. Sedangkan $46 \%$ dipengaruhi oleh unsur kondisi fisik misalnyaketepatan dan koordinasi.

\section{PEMBAHASAN}

Tujuan dalam penelitian ini adalah untuk mengetahuipowerotot lengan dengan kemampuan servis atas permainan bola voli. Secara teori dalam melakukan servis atas 
ditentukan oleh beberapa aspek biomotorik seperti kelenturan, ketepatan dan koordinasi. Aspek lain adanya postur tubuh yang ideal, akan tetapi yang menjadi fokus penelitian ini adalah aspek psikomotor khususnya mengenaipower otot lengan.

Berdasarkan analisis statistik dengan uji korelasi product moment ditemukan bahwa ada korelasi yang sangat kuat antara power otot lengan dengan kemampuan servisatas permainan bola voli, hal ini terlihat dari harga rxy yang diperoleh sebesar 0,73 dimana hasil ini jika dimasukan dipeta korelasi maka hubungan kedua variabel berada pada kategoti korelasi tinggi, selain itu menandakan adanya hubungan yang sangat bermakna hal ini terlihat dari perolehan nilai $\mathrm{r}$ hitung $=0,73>\mathrm{r}$ tabel $(\alpha 0,05=0,329)$. Sedangkan koefisien determinasi $\mathrm{r}^{2}=0,54$, yang berarti bahwa power otot lengan memberikan sumbangan atau kontribusi dengan kemampuan servis atas permainan bola voli sebesar $54 \%$. Besaran presentase kontribusi yang diberikan olehpowerotot lengan menggambarkan adanya hubungan atau korelasi antara variabel $\mathrm{X}$ dan variabel $\mathrm{Y}$ yang sangat signifikan.

Deskriptif hasil penelitian yang telah diuraikan satu persatu dapat dipastikan bahwa power otot lengan memiliki peran yang penting dalam servis atas permainan bola voli. Dengan demikian benar adanya bahwapower otot lengan memiliki hubungan yang signifikan dengan kemampuan servis atas permainan bola voli pada siswa SMA Negeri 2 Mawasangka.

\section{KESIMPULAN DAN SARAN}

Berdasarkan analisis data maka dalam penelitian ini dapat disimpulkan bahwa terdapat hubungan yang signifikan antara power otot lengan dengan kemampuan servis atas permainan bola voli, dimana koefisien korelasi $(\mathrm{rxy})=0,73>$ nilai $\mathrm{r}$ tabel $=0,329$, dengan koefisien determinasi $\mathrm{r}^{2}=0,73^{2}=0,54$ atau $54 \%$ artinya power otot lengan memberikan kontribusi atau sumbangan terhadap kemampuan servis atas permainan bola voli sebesar 54\%. Sedangkan $46 \%$ dipengaruhi oleh unsur kondisi fisik lainnya misalnyaketepatan, kelenturan dan koordinasi.

Berdasarkan hasil penelitian ini, maka penulis dapat memberikan saran-saran sebagai berikut:

1. Disarankan kepada guru pendidikan jasmani khususnya di SMA Negeri 2Mawasangka kiranya dapat memberikan mata pelajaran bola voli senantiasa menyertakan latihan-latihan power otot lengan dalam pembelajaran.

2. Disarankan kepada peneliti lain yang akan melakukan penelitian yang relevan dengan penelitian ini kiranya dapat mengungkap hubungan kemampuan fisik lain khususnya dalam menunjang kemampuan servis atas pada permainan bola voli.

\section{DAFTAR PUSTAKA}

Amung Ma'mun \& Toto Subroto, 2001. Pendekatan Keterampilan Taktis Dalam Permainan Bolavoli, Jakarta: Depdiknas.

Departemen Keolahragaan. 2006. Undang-Undang Republik Indonesia No. 3Tahun 2005 tentang Sistem Keolahragaan Nasional. Yogyakarta: PustakaYustisia

Kusumawati, Mia. (2015). Penelitian pendidikan penjasorkes. Bandung:Alfabeta. 
Muhammad Rusli, Abdul Saman : Hubungan Antara Power Otot Lengan Dengan Kemampuan Servis Atas Permainan Bola Voli Pada Siswa Sma Negeri 2 Mawasangka

Nurhasan, 1986. Tes dan Pengukuran Keolahragaan Diktat, Fakultas keguruan Olahraga dan Kesehatan IKIP Bandung.

Nuril Ahmadi. (2007). Panduan Olahraga Bola Voli. Surakarta: Era Pustaka Utama 